\title{
Aplikasi Ngresiki untuk Pelaporan Penumpukan Sampah Memanfaatkan Global Positioning System (GPS) dan Firebase
}

\author{
Astika Ayuningtyas ${ }^{1, *}$, Asih Pujiastuti ${ }^{2}$, Anggraini Kusumaningrum ${ }^{3}$, Nurcahyani Dewi Retnowati ${ }^{4}$, \\ Gabriel Naka Sorateleng 5 \\ 1,2,3,4,5 Informatic Study Program, Adisutjipto Institut of Aerospace Technology, Indonesia
}

Received: September 9, 2021; Accepted : October 7, 2021; Published : November 1, 2021

\begin{abstract}
Increasing human productivity accompanied by increasingly advanced developments has an impact on the need for faster and easier communication and data exchange, one of which is using a mobile smartphone. Ngresiki application is an application that is used to report the accumulation of garbage. Garbage accumulation is a problem that is often encountered, one of which is in Gunungkidul tourism objects, so there needs to be a solution to solve this problem. One solution is to utilize Global Positioning System (GPS) and Firebase technology to create a waste reporting application. The use of GPS can make it easier to report the accumulation of garbage in a place by utilizing geo tagging technology and the complexity of the features found in Firebase provide user convenience both in terms of application development and the use of features in applications that can facilitate reporting and recipients of waste reports. All functions in the Ngresiki Application run according to design. Tests in the field can show the location of the accumulation of waste with photos sent with the difference in the accuracy of the location where the report of accumulation of waste occurs 1.38 meters from the location point sent by the application. The average data transfer capability of the Ngresiki Application upload is $1161.8 \mathrm{~ms}$ for the reporting section and $1004.2 \mathrm{~ms}$ for the cleaning staff. Functional testing of photos uploaded to Firebase has gone through the process of automatically compressing photos with an average value percentage of $61.22 \%$ of the uploaded photo size.
\end{abstract}

Keywords: Global Positioning System, Firebase, Mobile Smartphone, Rubbish, Gunungkidul

\section{ABSTRAK}

Produktivitas manusia yang semakin meningkat diiringi dengan perkembangan jaman yang semakin maju berdampak pada kebutuhan komunikasi dan bertukar data yang semakin cepat dan mudah, salah satunya menggunakan mobile smartphone. Aplikasi Ngresiki merupakan sebuah aplikasi yang digunakan untuk melaporkan penumpukkan sampah. Penumpukan sampah merupakan permasalahan yang sering ditemui salah satunya di obyek wisata Gunungkidul sehingga perlu adanya solusi untuk menyelesaikan permasalahan tersebut. Salah satu solusi itu adalah dengan memanfaatkan teknologi Global Positioning System (GPS) dan Firebase untuk membuat sebuah aplikasi pelaporan sampah. Penggunaan GPS dapat memudahkan dalam pelaporan penumpukan sampah di suatu tempat dengan memanfaatkan teknologi geo tagging dan kompleksitas fitur yang terdapat pada Firebase memberikan kemudahan pengguna baik dari segi pengembangan aplikasi maupun penggunaan fitur dalam aplikasi yang dapat memudahkan pelapor dan penerima laporan sampah. Semua fungsi pada Aplikasi Ngresiki berjalan sesuai perancangan. Pengujian di lapangan dapat menunjukkan lokasi penumpukkan sampah dengan foto yang dikirim dengan selisih ketepatan lokasi terjadinya laporan penunumpukan sampah 1,38 meter dari titik lokasi yang dikirimkan oleh aplikasi. Kemampuan transfer data upload Aplikasi Ngresiki ratarata sebesar 1161,8 ms untuk bagian pelapor dan 1004,2 ms untuk bagian petugas kebersihan. Pengujian fungsional foto yang di-upload ke Firebase telah melalui proses pengkompresan foto secara otomatis dengan presentase nilai rata-rata $61,22 \%$ dari ukuran foto yang di-upload.

Kata Kunci: Global Positioning System, Firebase, Geo Tagging, Mobile Smartphone, Sampah, Gunungkidul

\section{LATAR BELAKANG MASALAH}

Tuntutan kebutuhan berkomunikasi dan bertukar data dengan cepat dan mudah membawa dampak yang cukup signifikan pada produktivitas manusia menggunakan mobile smartphone. Menurut kamus Bahasa Inggris, mobile berarti dapat bergerak dengan bebas dan mudah [1], tetapi dapat pula diartikan sebagai sebuah teknologi digital yang dapat dibawa atau digerakan tanpa menggunakan kabel (wireless) [2]. Teknologi wireless berkembang begitu cepat untuk memenuhi tuntutan pengguna yang membutuhkan komunikasi dengan kecepatan tinggi, kapasitas (broadband) besar serta dengan mobilitas yang tinggi menuju broadband mobile 
communication [3]. Terlihat bahwa trend ke depan adalah setiap teknologi harus terkoneksi satu sama lain sehingga tercipta suatu konvergensi [4]. Berbagai jenis aplikasi yang ditawarkan bukan hanya untuk keperluan komunikasi saja tetapi telah merambah untuk seluruh bidang [5] salah satunya di bidang kebersihan lingkungan.

Pemerintah Kabupaten Gunungkidul, Daerah Istimewa Yogyakarta adalah salah satu daerah yang memiliki banyak tempat wisata (contohnya daerah Patuk, Wonosari, Playen, Karangmojo) dan gencar menggalakan seluruh pihak untuk saling bekerja sama menjaga kebersihan di kawasan wisata [6]. Permasalahan sampah menjadi salah satu perhatian Pemerintah Kabupaten (PEMKAB) dan berkomitmen untuk menciptakan kondisi lingkungan yang bersih dan selalu memberikan kenyamanan [7]. Korelasi antara masyarakat khususnya pengelola tempat wisata dengan Dinas Kebersihan Gunungkidul sangat dibutuhkan demi terwujudnya lingkungan sehat dan nyaman bagi masyarakat dalam melakukan kegiatan sehari-hari [8][9][10]. Dukungan dari sisi teknologi sangat diperlukan guna menunjang laporan penumpakan sampah, salah satunya adalah dibuatnya aplikasi pelaporan sampah yang dapat membantu masyarakat dalam melaporakan penumpukan sampah yang terjadi di wilayahnya. Di sisi lain, juga diperlukan aplikasi untuk Petugas Dinas Kebersihan guna mendapatkan informasi dimana terjadinya penumpukan sampah yang terintegrasi dengan aplikasi pelaporan sampah. Terintegrasi yang dimaksud adalah saling terhubungnya data penumpukan sampah dan informasi lokasi ada pada aplikasi pelaporan sampah yang akan diberi nama Ngresiki dalam bahasa Indonesia berarti bersih-bersih.

Aplikasi pelaporan penumpukkan sampah dibutuhkan performa tinggi dalam pengolahan data [11] serta kompleksitas fitur yang dapat digunakan untuk memudahakan pelapor dan penerima laporan. Google menawarkan sebuah platform Backend as a Service (BaaS) yang diberi nama Firebase [12], yang memiliki kompleksitas fitur dan fungsi dengan performa yang tinggi, serta kemudahan dalam penggunaannya baik dari segi pengembangan aplikasi maupun penggunaan fitur dalam aplikasi [13][14] yang dapat memudahkan pelapor dan penerima laporan sampah. Selain itu, pemanfaatan teknologi Global Positioning System (GPS) [15] untuk memudahkan dalam pelaporan penumpukan sampah di suatu tempat dengan memanfaatkan teknologi geo tagging [11]. Saat ini GPS sudah banyak digunakan orang di seluruh dunia dalam berbagai bidang aplikasi yang menuntut informasi tentang posisi, kecepatan dan percepatan waktu yang teliti [16] untuk menghasilkan lokasi sesuai dengan keadaaan sebenarnya [16]. Aplikasi pelaporan penumpukan sampah dengan memanfaatkan GPS dapat memudahkan masyarakat dalam pelaporan titik dimana sampah terkumpul yang tidak diketahui oleh petugas kebersihan sebelumnya [17] dan Firebase dapat memberikan informasi kepada pengguna aplikasi mengenai posisi letak penumpukan sampah dan posisi pengguna yang dapat berubah secara real-time [18][19].

\section{METODE PENELITIAN}

Penelitian ini menggunakan penelitian lapangan (field research) dengan cara mengumpulkan data melalui pengamatan secara langsung orang-orang dan keadaan lokasi penelitian yang akan dijadikan acuan dalam pembahasan permasalahan ini. Metode pengumpulan data yang dipakai adalah observasi dan wawancara untuk memperoleh data primer serta studi literatur untuk mendapatkan data sekunder.

a. Data Primer

Data primer diperoleh dari kegiatan observasi langsung terhadap obyek yang akan diteliti yaitu di obyek wisata Gunungkidul, Daerah Istimewa Yogyakarta (DIY).

b. Data Sekunder

Data sekunder diperoleh melalui studi literatur seperti jurnal, prosiding, buku dan bacaan-bacaaan yang berkaitan dengan permasalahan penelitian.

\subsection{Pengumpulan Data}

Pengolahan data dalam penelitian ini terdiri dari dua bagian yaitu reduksi data dan koding data. Reduksi data dilakukan untuk mengurangi atau memilah-milah data yang sesuai dengan topik permasalahan, sedangkan koding data dilakukan untuk menyesuaikan data yang didapatkan baik melalui kepustakaan atau penelitian lapangan sesuai dengan pokok permasalahan. Analisis data yang dilakukan menggunakan kualitatif dengan mengumpulkan, memilah-milah, mengklasifikasikan dan mencatat yang dihasilkan catatan lapangan. Data yang dikumpulkan digunakan untuk menganalisis kebutuhan masukan dan keluaran pada perancangan sistem yang dibuat. Adapun data masukan yang digunakan pada aplikasi adalah data pengguna untuk tujuan mengautentifikasi baik pelapor atau petugas kebersihan, selain itu data foto penumpukan sampah beserta dengan lokasi pengguna untuk mengetahui lokasi pelaporan yang akan dieksekusi oleh petugas kebersihan 
Aplikasi Ngresiki untuk Pelaporan Penumpukan Sampah Memanfaatkan Global Positioning System....

sedangkan data keluaran dari sistem adalah data foto hasil eksekusi petugas kebersihan beserta dengan lokasinya.

\subsection{Analisis Perancangan Sistem}

Perancangan sistem menggunakan metode Unified Modelling Language (UML), bertujuan untuk memodelkan suatu sistem yang dapat mudah dipahami oleh manusia maupun mesin. UML yang digunakan yaitu Use Case Diagram, Activity Diagram, Class Diagram dan Entity Relationship Diagram. Use Case Diagram berisikan diagram penggunaan pada setiap actor atau pengguna dimana dalam kasus ini digunakan oleh dua actor yaitu masyarakat dalam hal ini pengelola wisata dan petugas Kebersihan. Gambar dari Use Case Diagram dapat dilihat pada Gambar 1.

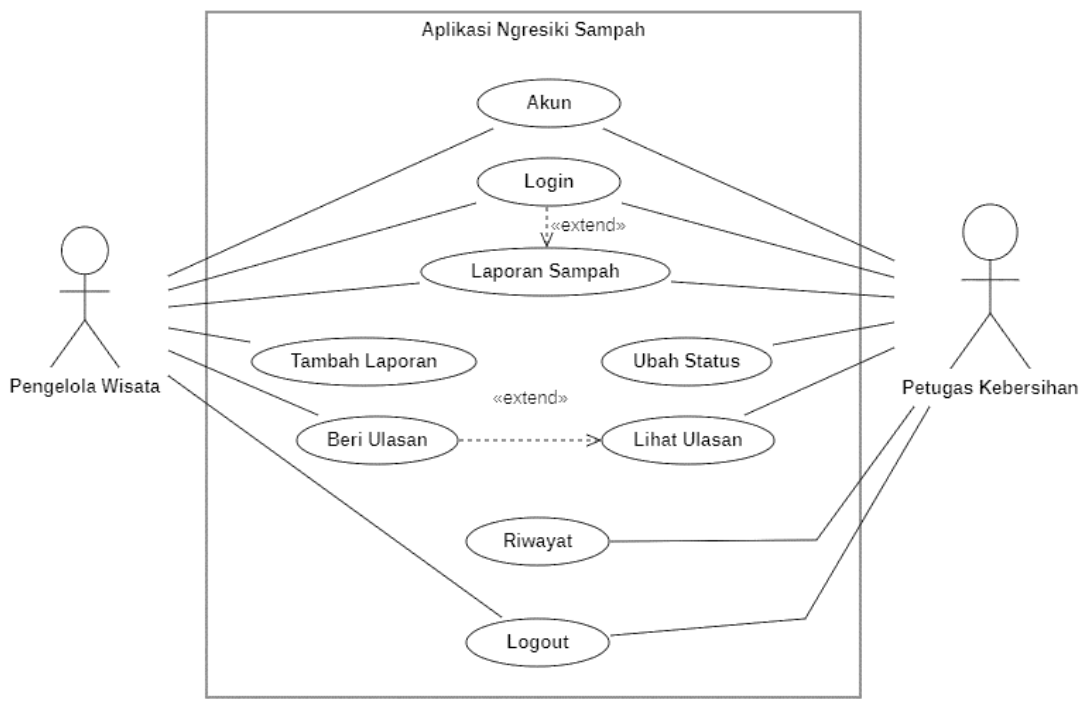

Gambar 1 Use Case Diagram Aplikasi Ngresiki

Activity Diagram menunjukkan aktivitas penggunaan secara lengkap dari awal dimulainya sistem hingga sistem dimatikan atau ditutup. Pada Gambar 2 ditunjukkan 2 activity yaitu activity Aplikasi Ngresiki sebagai client, activity Firebase sebagai server. Kedua activity client dimulai dengan login yang akan diteruskan kepada server, apakah akun dan password sudah benar atau belum, jika sudah benar maka akan diteruskan ke menu laporan, namun jika id dan password salah maka dialihkan ke tampilan login untuk melakukan pengisian ulang id dan password. Pada Menu Petugas kebersihan akan disajikan daftar laporan sampah. Petugas kebersihan dapat melihat detail laporan dengan memilih laporan sampah pada daftar laporan. Setelah masuk ke screen detail, petugas kebersihan dapat melihat lokasi. Pada Menu pengelola wisata akan terfokus pada laporan sampah yang terjadi di wilayah tempat wisata tersebut pada Floating Action Button (FAB) yang ditunjukkan dengan icon kamera yang berfungsi untuk tambah laporan, yaitu menambah laporan penumpukan sampah. Pengelola wisata dapat pula memberikan ulasan pada petugas kebersihan pada tab ulasan. 


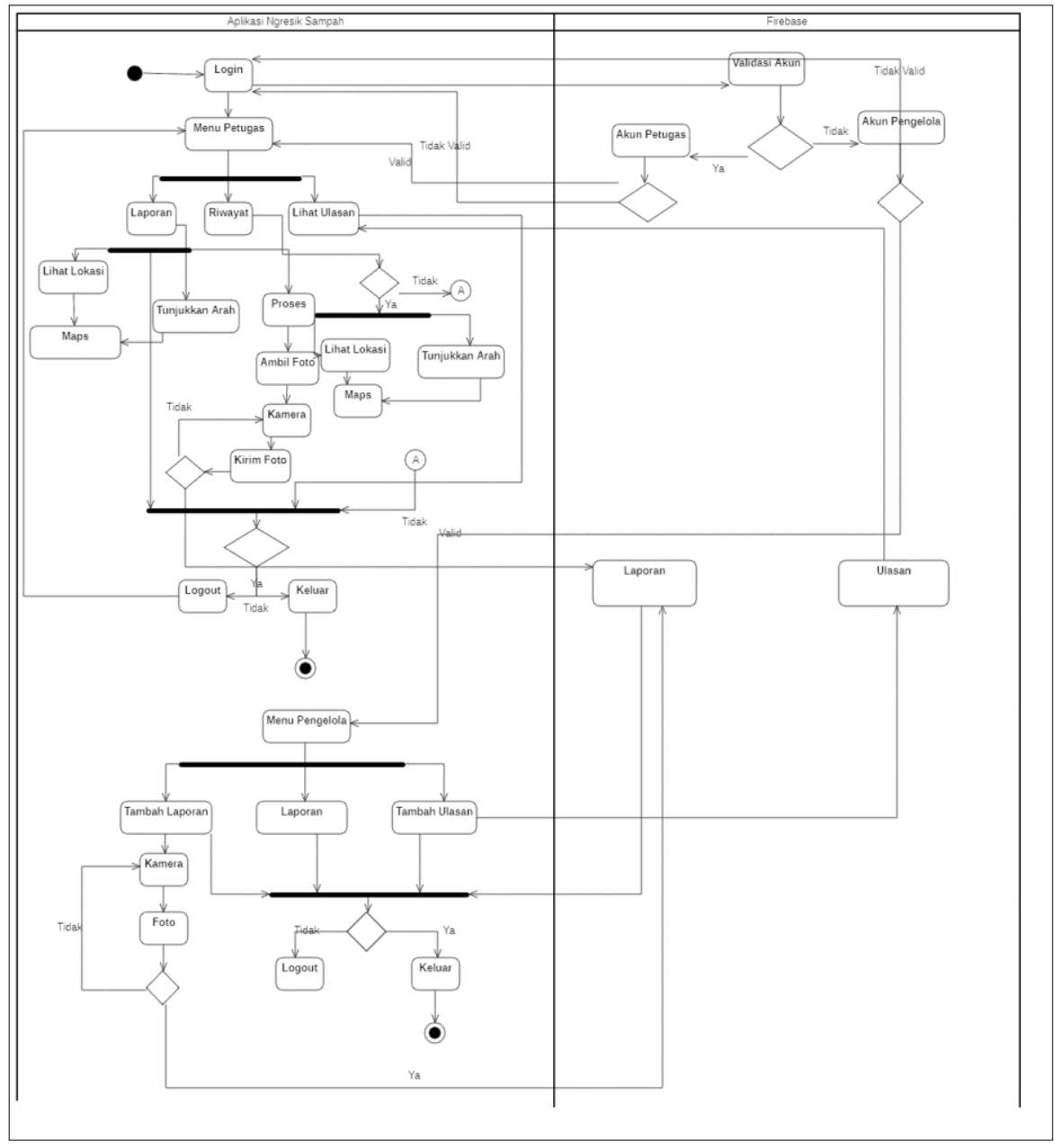

Gambar 2. Activity Diagram Aplikasi Ngresiki

Aplikasi Ngresiki yang dikhususkan kepada petugas kebersihan dan ppengelola wisata (pelapor) diimplementasikan pada smartphone Android yang dapat diunduh pada Playstore (Gambar 3).



(a)



(b)

Gambar 3 Perancangan Interface Aplikasi Ngresiki 
Aplikasi Ngresiki untuk Pelaporan Penumpukan Sampah Memanfaatkan Global Positioning System....

\section{HASIL DAN ANALISIS}

Hasil dari aplikasi pelaporan penumpukan sampah yang diberi nama Ngresiki dapat dilihat pada Gambar 5. Pada menu petugas kebersihan dan pelapor, implementasi User Interface yang pertama adalah SplashScreen selama 1 detik lalu dilanjukan dengan tampilan Login (Gambar 4).

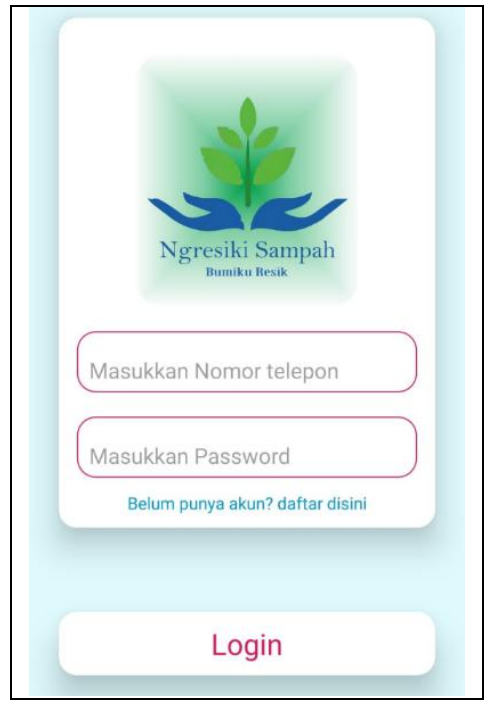

Gambar 4. Halaman Awal Aplikasi Ngresiki

Pada screen ini (Gambar 5) terdapat daftar laporan sampah yang telah dilaporkan oleh pengelola wisata menampilkan koordinat lokasi penumpukan sampah. Daftar laporan sampah ketika ditekan akan menuju ke screen proses laporan yang terdapat 3 tombol, Lihat Lokasi, Tunjukan Arah dan Proses seperti pada Gambar 6. Pada tombol Lihat Lokasi ketika ditekan akan mengakses Google street view, tombol Tunjukan Arah ketika ditekan akan membuka Google Maps dan otomatis akan langsung mengarahkan lokasi laporan sampah. Petugas akan langsung diarahkan menuju ke lokasi penumpukan sampah tanpa harus memasukan nama wilayah maupun mengetikan titik koordinat di Google Maps. Tombol Proses berfungsi untuk merubah status laporan sampah yang dari "Belum dikerjakan" menjadi "Sedang dikerjakan".

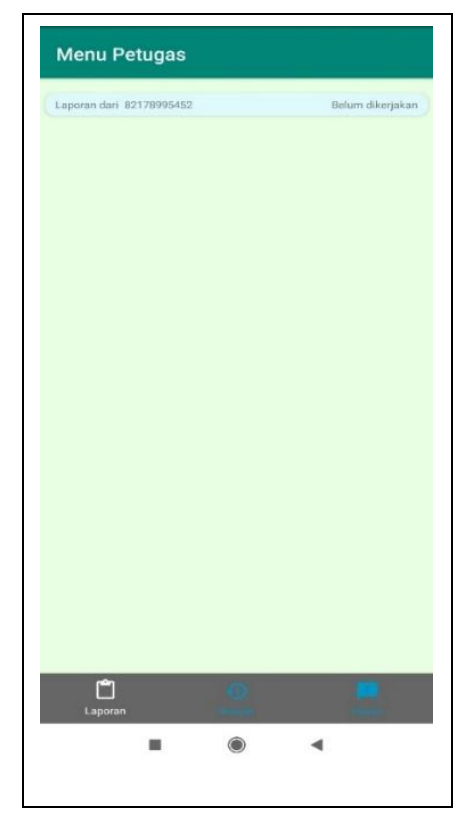

Gambar 5 Screenshoot Halaman Laporan Sampah 


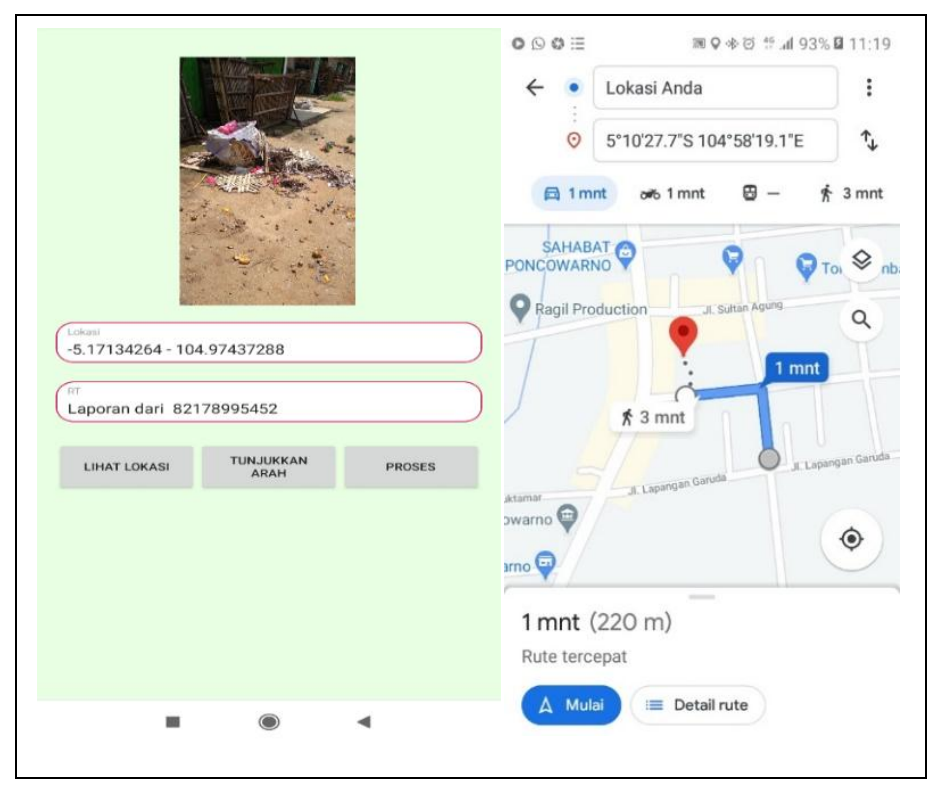

Gambar 6 Screenshoot Halaman Detail Laporan Sampah

Berdasarkan hasil pengujian yang telah dilakukan yaitu pengujian sistem aplikasi Ngresiki Sampah dengan uji fungsionalitas. Uji fungsionalitas dilakukan dengan menguji tiap-tiap baris kode dengan ekspetasi apakah fungsi hasil kode berhasil atau tidak. Terdapat beberapa aspek yang harus di uji apakah pengujian kecepatan transfer data antara client dan server apakah fitur realtime database yang dimplementasikan berfungsi dengan baik atau tidak. Dalam test kecepatan internet berlangsung ada 3 hal yaitu Ping, (latency), download dan Upload. Ping (Packet Internet Gopher) adalah alat jaringan untuk mengukur reaksi server. Sedangkan latency adalah ukuran waktu dari reaksi koneksi internet tersebut, apakah ukuran gambar mempengaruhi kecepatan proses upload dan download, aplikasi dapat berjalan dengan spesifikasi yang sama namu bebeda merk handphone, apakah ketepatan lokasi dapat sesuai dengan lokasi yang terjadinya penumpukan sampah dan provider penyedia layanan internet mempengaruhi kecepatan transfer data.

Uji fungsionalitas dilakukan dengan pengujian terhadap 3 versi Android yang berbeda dan kecepatan transaksi dengan 3 provider yang berbeda, Tabel 1 adalah cuplikan hasil pengujian kode baris dan Tabel 2 adalah hasil pengujian kecepatan transfer data:

Tabel 1 Cuplikan Hasil Uji Fungsionalitas Aplikasi Ngresiki Sampah Menu Petugas

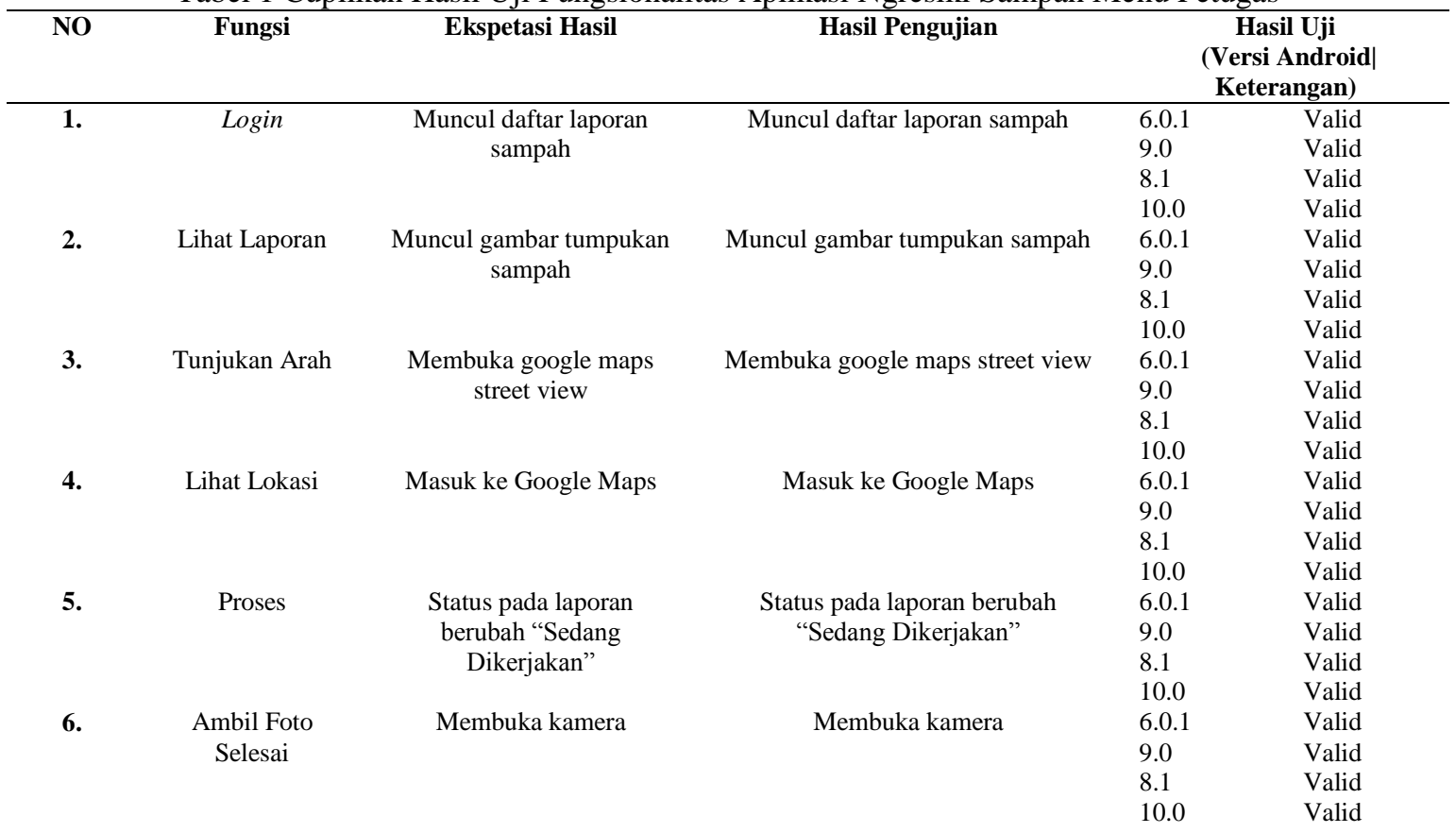


Aplikasi Ngresiki untuk Pelaporan Penumpukan Sampah Memanfaatkan Global Positioning System....

\begin{tabular}{|c|c|c|c|c|c|}
\hline 7. & Submit & $\begin{array}{l}\text { Status laporan berubah } \\
\text { menjadi "Selesai } \\
\text { Dikerjakan" dan laporan } \\
\text { telah pindah ke riwayat }\end{array}$ & $\begin{array}{l}\text { Status laporan berubah menjadi } \\
\text { "Selesai Dikerjakan" dan laporan } \\
\text { telah pindah ke riwayat }\end{array}$ & $\begin{array}{l}6.0 .1 \\
9.0 \\
8.1 \\
10.0\end{array}$ & $\begin{array}{l}\text { Valid } \\
\text { Valid } \\
\text { Valid } \\
\text { Valid }\end{array}$ \\
\hline 8. & Riwayat & $\begin{array}{l}\text { Daftar laporan sampah } \\
\text { yang telah dikerjakan }\end{array}$ & $\begin{array}{c}\text { Daftar laporan sampah yang telah } \\
\text { dikerjakan }\end{array}$ & $\begin{array}{l}6.0 .1 \\
9.0 \\
8.1 \\
10.0\end{array}$ & $\begin{array}{l}\text { Valid } \\
\text { Valid } \\
\text { Valid } \\
\text { Valid }\end{array}$ \\
\hline 9. & Ulasan & $\begin{array}{l}\text { Muncul ulasan dari } \\
\text { pengelola }\end{array}$ & Muncul ulasan dari pengelola & $\begin{array}{l}6.0 .1 \\
9.0 \\
8.1 \\
10.0\end{array}$ & $\begin{array}{l}\text { Valid } \\
\text { Valid } \\
\text { Valid } \\
\text { Valid }\end{array}$ \\
\hline
\end{tabular}

Tabel 2 Cuplikan Hasil Uji Fungsionalitas Aplikasi Ngresiki Sampah Menu Pengelola

\begin{tabular}{|c|c|c|c|c|c|}
\hline NO & Fungsi & Ekpetasi Hasil & Hasil Pengujian & \multicolumn{2}{|c|}{$\begin{array}{c}\text { Hasil Uji } \\
\text { (Versi Android| } \\
\text { Keterangan) }\end{array}$} \\
\hline 1. & Tambah Laporan & Daftar laporan bertambah & Daftar laporan bertambah & $\begin{array}{c}6.0 .1 \\
9.0 \\
8.1 \\
10.0\end{array}$ & $\begin{array}{l}\text { Valid } \\
\text { Valid } \\
\text { Valid } \\
\text { Valid }\end{array}$ \\
\hline 2. & Perubahan Status & $\begin{array}{l}\text { Muncul status "Belum Dikerjakan, } \\
\text { Sedang Dikerjakan, Selesai Dikerjakan" }\end{array}$ & $\begin{array}{l}\text { Muncul status "Belum } \\
\text { Dikerjakan, Sedang Dikerjakan, } \\
\text { Selesai Dikerjakan" }\end{array}$ & $\begin{array}{c}6.0 .1 \\
9.0 \\
8.1 \\
10.0\end{array}$ & $\begin{array}{l}\text { Valid } \\
\text { Valid } \\
\text { Valid } \\
\text { Valid }\end{array}$ \\
\hline 3. & Lihat Laporan & $\begin{array}{l}\text { Muncul Foto sebelum dan sesudah } \\
\text { Sampah dibersihkan }\end{array}$ & $\begin{array}{l}\text { Muncul Foto sebelum dan } \\
\text { sesudah Sampah dibersihkan }\end{array}$ & $\begin{array}{c}6.0 .1 \\
9.0 \\
8.1 \\
10.0\end{array}$ & $\begin{array}{l}\text { Valid } \\
\text { Valid } \\
\text { Valid } \\
\text { Valid }\end{array}$ \\
\hline 4. & Kirim Laporan & Daftar laporan Bertambah & Daftar laporan Bertambah & $\begin{array}{c}6.0 .1 \\
9.0 \\
8.1 \\
10.0\end{array}$ & $\begin{array}{l}\text { Valid } \\
\text { Valid } \\
\text { Valid } \\
\text { Valid }\end{array}$ \\
\hline 5. & Tambah Ulasan & Ulasan terkirim ke menu petugas & Ulasan terkirim ke menu petugas & $\begin{array}{c}6.0 .1 \\
9.0 \\
8.1 \\
10.0\end{array}$ & $\begin{array}{l}\text { Valid } \\
\text { Valid } \\
\text { Valid } \\
\text { Valid }\end{array}$ \\
\hline
\end{tabular}

Hasil uji fungsionalitas aplikasi Ngresiki Sampah sesuai dengan hasil perancangan sistem. Fitur-fitur yang ada pada aplikasi mempunyai keterangan valid dimana sistem tidak mengalami kendala saat dioperasikan di sistem operasi Android 6.0.1 sampai dengan Android 10.0.

Tabel 3 Hasil Uji Fungsionalitas pada Kecepatan Transfer Data dan Hasil Kompres Foto Berdasarkan




Pada Tabel 3 hasil uji fungsionalitas aplikasi Ngresiki Sampah gambar atau foto yang di-upload ke firebase telah terkompres dengan hasil rata-rata gambar $648 \mathrm{~kb}$ dan mempunyai presentase $61,218 \%$. Kecepatan transfer data aplikasi Ngresiki menggunakan 5 smartphone dan 5 provider menghasilkan kecepatan rata-rata pada sisi pelapor untuk upload laporan adalah 1161,8 ms, untuk sisi petugas mempunyai kecepatan rata-rata upload 1004,2ms. Kecepatan download dari sisi petugas untuk melihat foto laporan yang telah dikirimkan oleh pengelola wisata mempunyai kecepatan rata-rata 1300,2ms. Kecepatan cek lokasi pada sisi petugas mempunyai nilai rata-rata 1925,6ms dan untuk kecepatan cek rute mempunyai nilai rata-rata 2050ms. Perbedaan kecepatan transfer data dan hasil kompres foto pada aplikasi dipengaruhi oleh provider dan smartphone yang digunakan untuk pengujian.

Tabel 4. Hasil Uji Fungsionalitas Ketepatan Lokasi pada Titik Laporan

\begin{tabular}{|c|c|c|c|}
\hline NO & Nomor Laporan & Lokasi Obyek & Selisih (meter) \\
\hline 1 & 1604551939403 & 2 & 1 \\
\hline 2 & 1604721157044 & 4 & 2 \\
\hline 3 & 1604721242079 & 4 & 0,5 \\
\hline 4 & 1604726981692 & 4 & 1 \\
\hline 5 & 1604727098631 & 4 & 1 \\
\hline 6 & 1604727172682 & 4 & 1 \\
\hline 7 & 1604727203425 & 4 & 1 \\
\hline 8 & 1604727854404 & 9 & 1 \\
\hline 9 & 1604806870756 & 4 & 1 \\
\hline 10 & 1604807006467 & 4 & 1 \\
\hline 11 & 1605082592129 & 6 & 3 \\
\hline 12 & 1605082648194 & 4 & 1 \\
\hline 13 & 1605082668494 & 4 & 1 \\
\hline 14 & 1605082686066 & 4 & 3 \\
\hline 15 & 1605082779859 & 12 & 1 \\
\hline 16 & 1605597495654 & 18 & 2 \\
\hline 17 & 1605690918171 & 6 & 1 \\
\hline 18 & 1607159497568 & 6 & 2 \\
\hline 19 & 1607159585266 & 5 & 1 \\
\hline 20 & 1607159784866 & 5 & 1 \\
\hline 21 & 1606520581897 & 5 & 1 \\
\hline 22 & 1606639565016 & 14 & 2 \\
\hline 23 & 1606758548136 & 27 & 3 \\
\hline 24 & 1606877531255 & 21 & 1 \\
\hline 25 & 1606996514375 & 22 & 1 \\
\hline 26 & 1607115497494 & 6 & 2 \\
\hline 27 & 1607234480614 & 6 & 1 \\
\hline 28 & 1607353463733 & 8 & 2 \\
\hline 29 & 1607472446853 & 9 & 1 \\
\hline 30 & 1607591429972 & 9 & 1 \\
\hline \multicolumn{3}{|c|}{ Hasil Rata-rata titik sampah dengan lokasi yang dikirimkan } & $1,383 \mathrm{~m}$ \\
\hline
\end{tabular}

Hasil dari uji fungsionalitas ketepatan titik lokasi sampah yang dikirimkan (terlihat pada Tabel 4) oleh pengelola wisata mempunyai nilai rata-rata 1,383 meter.

\section{KESIMPULAN}

Berdasarkan perancangan, implementasi dan pengujian pada Aplikasi Nawani dan Nukoni, dapat diambil beberapa kesimpulan:

1. Berdasarkan pengujian secara fungsional, Aplikasi Ngresiki pada pengujian semua fitur berjalan lancer dan tidak mengalami kendala saat dioperasikan di sistem operasi Android 6.0.1 sampai dengan Android 10.0.

2. Berdasarkan pengujian secara langsung di lapangan, Aplikasi Ngresiki dapat menunjukkan lokasi penumpukan sampah dengan foto yang dikirim oleh pengelola wisata (pelapor) kepada petugas kebersihan.

3. Berdasarkan pengujian fungsional dengan kecepatan transfer data, Aplikasi Ngresiki memiliki kemampuan transfer data upload rata-rata $1161,8 \mathrm{~ms}$ pada bagian menu petugas dan $1004,2 \mathrm{~ms}$ bagian menu pelapor.

4. Berdasarkan uji fungsional, foto yang di-upload ke Firebase telah melalui proses pengkompresan foto secara otomatis dengan presentase rata-rata $61,218 \%$ dari ukuran foto yang di-upload.

5. Berdasarkan uji fungsional ketepatan lokasi terjadinya laporan penumpukan sampah mmpunyai selisih 1,383 meter dari titik lokasi yang dikirimkan oleh Aplikasi Ngresiki. 


\section{UCAPAN TERIMA KASIH OPSIONAL}

Terima kasih kepada Direktorat Penelitian dan Pengabdian kepada Masyarakat Direktorat Jenderal Penguatan Penelitian dan Pengembangan (DRPM) Kementrian Riset dan Teknologi (Kemristekdikti) Republik Indonesia atas dukungan yang diberikan kepada penulis berupa bantuan dana penelitian tahun 2021 dengan skema Penelitian Dosen Pemula (PDP) dan Institut Teknologi Dirgantara Adisutjipto Yogyakarta yang telah mendukung untuk melaksanakan salah satu Tridharma perguruan tinggi.

\section{DAFTAR PUSTAKA}

[1] Y. Effendi, "Rancangan Aplikasi Game Edukasi Berbasis Mobile Menggunakan App Inventor," J. Intra-Tech, vol. 2, no. 1, hal. 39-48, 2018.

[2] A. Y. Pratama, Y. Rahma, dan F. Nugraha, “'Bang Sam' Sebagai Media Pengelolaan Bahan Baku Kerajinan Hasil Sampah Berbasis Mobile Pada Bank Sampah Sekarmelati Di Kabupaten Kudus," Simetris J. Tek. Mesin, Elektro dan Ilmu Komput., vol. 9, no. 2, hal. 909-918, 2018, doi: 10.24176/simet.v9i2.2438.

[3] J. Manajemen, "Analisis Penerapan Teknologi Jaringan Lte 4G Di Indonesia Fadhli Fauzi, Gevin Sepria Harly, Hanrais Hs," Maj. Ilm. UNIKOM, vol. 10, no. 2, hal. 281-290.

[4] M. Danuri, "Development and Transformation of Digital Technology," Infokam, vol. XV, no. II, hal. 116-123, 2019.

[5] R. Rachmawati, "Pengembangan Perkotaan dalam Era Teknologi Informasi dan Komunikasi," hal. 246, 2014, [Daring]. Tersedia pada: https://books.google.com/books?hl=en\&lr=\&id=bNBWDwAAQBAJ\&oi=fnd\&pg=PR1\&dq=PEMANFAATAN +TEKNOLOGI+INFORMASI+DAN+KOMUNIKASI+OLEH+PEGAWAI+DI+DINAS+PENDIDIKAN+KOT A+YOGYAKARTA\&ots=AEvGEHo56h\&sig=ZB5qUkpI8a1TuRvpGOvYhiQrYNE\%0Ahttps://books.google.c om.au/books?id.

[6] M. A. Sari, "PESONA PANTAI INDRAYANTI SEBAGAI DAYA TARIK WISATA DI GUNUNGKIDUL." 2018 Sekolah Tinggi Pariwasata Ambarrukmo Yogyakarta.

[7] A. Mulasari, A. H. Husodo, dan N. Muhajir, "Situation Analysis of Waste Problem in Yogyakarta," J. Kesehat. Lingkung. Indones. KEMAS, vol. 11, no. 2, hal. 98-106, 2016.

[8] S. Sudaryanto, "Implementasi Kebijakan Pengembangan Pariwisata Kabupaten Gunungkidul," hal. xii, 2019, [Daring]. Tersedia pada: http://repo.apmd.ac.id/760/.

[9] A. Pramono dan I. H. Dwimawanti, "Strategi Pengembangan Obyek Wisata Pantai di Kabupaten Gunungkidul," J. Public Policy Manag. Rev., vol. 6, no. 3, hal. 280-292, 2017, [Daring]. Tersedia pada: https://ejournal3.undip.ac.id/index.php/jppmr/article/view/16741.

[10] J. M. Masjhoer, "Partisipasi Pelaku Usaha Pariwisata dalam Pengelolaan Sampah di Pantai Pulang Sawal, Kabupaten Gunungkidul, Yogyakarta," J. Pariwisata Terap., vol. 2, no. 2, hal. 122, 2018, doi: 10.22146/jpt.43179.

[11] D. Apriliani dan Maesaroh, "Efektivitas Pengelolaan Sampah Kota Semarang Melalui Program Silampah (Sistem Lapor Sampah)," J. Public Policy Manag. Rev., vol. 10, no. 1, hal. 272-285, 2021.

[12] C. Khawas dan P. Shah, "Application of Firebase in Android App Development-A Study," Int. J. Comput. Appl., vol. 179, no. 46, hal. 49-53, 2018, doi: 10.5120/ijca2018917200.

[13] N. Chatterjee, S. Chakraborty, A. Decosta, dan A. Nath, "Real-time Communication Application Based on Android Using Google Firebase," Ddfsdfdsfsd, vol. 6, no. 4, hal. 74-79, 2018, [Daring]. Tersedia pada: www.ijarcsms.com.

[14] A. Pujiastuti, A. Ayuningtyas, A. Kusumaningrum, dan A. D. Saputra, "Nawani and Nukoni Applications for Supporting Small and Medium Micro Enterprises in Gunungkidul District," Angkasa J. Ilm. Bid. Teknol., vol. 13, no. 1, hal. 15-26, 2021, doi: 10.28989/angkasa.v13i1.807.

[15] H. Hutrianto dan A. Putra, "IMPLEMENTASI SCRUM MODEL DALAM PENGEMBAGNAN APLIKASI pelAPORAN SAMPAH SEBAGAI WUJUD SMART CLEANING," JIPI (Jurnal Ilm. Penelit. dan Pembelajaran Inform., vol. 5, no. 1, hal. 9, 2020, doi: 10.29100/jipi.v5i1.1552.

[16] C. N. Azizah dan M. I. Firdaus, "PEMANFAATAN GPS NAVIGASI UNTUK PEMETAAN BATAS KELURAHAN (Studi Kasus di Kelurahan Jogoyudan, Kecamatan Lumajang, Jawa Timur),” Semin. Nas. Geomatika, no. April, hal. 561, 2021, doi: 10.24895/sng.2020.0-0.1169.

[17] S. Bahri, S. Suhada, dan J. M. Hudin, "Teknologi Global Positioning Sistem (GPS) Untuk Pelaporan Dan Penjemputan Sampah Berbasis Android," Comput. Eng. Sci. Syst. J., vol. 4, no. 1, hal. 39, 2019, doi: 10.24114/cess.v4i1.11358.

[18] Y. H. Femi Dwi Astuti, "PEMANFAATAN FIREBASE REALTIME DATABASE PADA APLIKASI PEMBELAJARAN AGAMA ISLAM MENGGUNAKAN FRAMEWORK FLUTTER."

[19] L. B. Service, "Pemanfaatan Teknologi Firebase Dan Location Based Service Berbasis Android Sebagai Media Pemesan Makan Dan Minuman Pada Rumah Makan P-ISSN : 2089-676X,” vol. 10, no. 1, hal. 50-53, 2021. 
